Detalhe da Baia da Guanabara, Duguay-Trouin (1740).

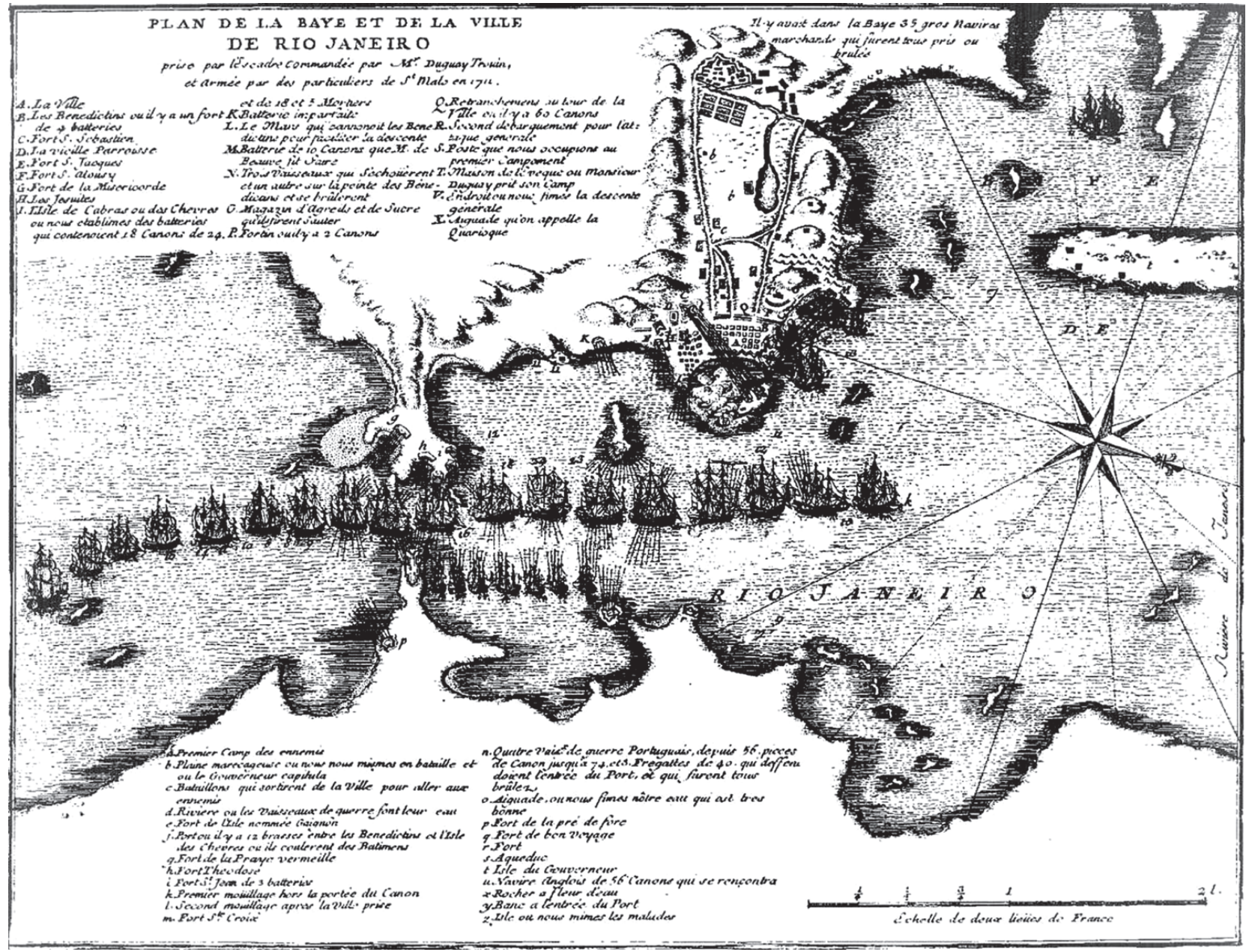




\title{
Em Defesa do Território: Expansão Metropolitana e Lutas Sociais
}

\section{Floriano José Godinho de Oliveira*}

\begin{abstract}
Resumo: A reestruturação produtiva tem promovido alterações significativas nos espaços urbanos e metropolitanos, delineando novos papéis para as cidades centrais e expandindo o território metropolitano. O texto apresenta alguns referenciais para o acompanhamento desse processo e analisa aspectos importantes da expansão em curso no espaço fluminense. O objetivo central do artigo é examinar até que ponto projetos voltados para administrar e promover essas mudanças apresentam a preocupação em incorporar reconhecimento e participação dos sujeitos sociais que habitam a metrópole. O artigo destaca que os desafios postos pela gestão das mudanças, caso sejam conjugados com uma expansão da participação popular, abrem novo campo de lutas para os movimentos sociais urbanos.
\end{abstract}

Palavras-chave: Área metropolitana; área metropolitana do Rio de Janeiro; participação popular; movimentos sociais no Rio de Janeiro.

\begin{abstract}
The structural changes of productive system have been promoting significant changes on metropolitan and urban spaces, reassigning new functions for the central cities and have expanded metropolitan territory. This article is concerned with those changes and the new uses of territory, aiming to observe the role assigned to social subjects and popular participation on this process. It offers some new patterns for examining the State of Rio de Janeiro analyzing important aspects related to those changes and concludes by point out the great opportunity they bring to urban social movements so long as the popular participation in the territorial management increases.

Keywords: Metropolitan area; metropolitan area of Rio de Janeiro; popular participation; socials movements of Rio de Janeiro.
\end{abstract}

\section{Introdução}

Em pouco mais de quarenta anos, os espaços metropolitanos no mundo passaram por transformações territoriais tão intensas que hoje somos obrigados a rever conceitos e redefinir analiticamente as metrópoles. E rever não somente os aspectos

\footnotetext{
* Professor adjunto do Departamento de Geografia da Faculdade de Formação de Professores da Universidade do Estado do Rio de Janeiro. Doutor em Geografia Humana pela Universidade de São Paulo. Mestre em Planejamento Urbano e Regional pela Universidade Federal do Rio de Janeiro. Bolsista do Programa Prociência da FAPERJ/UERJ. Atualmente, realiza estágio pós-doutoral na Universidade de Barcelona, Espanha. Endereço postal: Rua Dr. Francisco Portela, 1.470, Patronato, São Gonçalo, Rio de Janeiro, CEP: 24435.000. Endereço eletrônico: fgodinho@uerj.br.
} 
espaciais, como as novas delimitações e dinâmicas de adensamento urbano dessas áreas, mas sobretudo as novas perspectivas de gestão institucional e participação social para garantir governabilidade e melhores condições de vida e urbanidade nas metrópoles.

O adensamento e a expansão espacial das áreas urbanas das grandes cidades industriais é um fenômeno que se torna expressivo no decorrer da década de 1960, e que colocou, definitivamente, as áreas metropolitanas como um dos fenômenos socioespaciais mais importantes a serem compreendidos. Espaço privilegiado de produção industrial, a metrópole trouxe consigo o germe de um crescimento incontrolável, agregando investimentos, atividades econômicas de todos os tipos e sobretudo um fluxo populacional crescente, que vai à cidade em busca de oportunidades de trabalho.

A ganância de lucros por parte dos setores das classes dominantes e empresariais, em um primeiro momento, fez com que não lhes importassem as consequências da falta de planejamento nesses espaços. Imersos em uma lógica empresarial e protegidos por todo o aparato produzido em determinadas áreas da cidade - áreas que podemos denominar de luminosas, segundo a definição de Milton Santos (SANTOS, 1996) -, as classes dominantes e suas respectivas formas de domínio nas esferas do Estado e governos nada fizeram para que esse crescimento fosse minimamente controlado e administrável.

Com o esgotamento do modelo de produção denominado fordista ${ }^{1}$ e a instauração de um amplo processo de reestruturação produtiva, organizada pelos setores industriais e financeiros como forma de superar a crise econômica que atingiu os países mais industrializados nos anos 1970, por meios do uso de novas tecnologias e aprimoramento dos sistemas comunicacionais, surge a perspectiva de que a tendência à concentração urbana e metropolitana se reverta. Muitas foram as tendências apontadas nos estudos urbanos e regionais: desconcentração, descentralização, desindustrialização das metrópoles, crescimento dirigido às cidades médias e inúmeras outras perspectivas foram anunciadas, mas a retomada do crescimento econômico no início do século XXI desfez as dúvidas e a metrópole voltou a ser o centro espacial da direção e da realização das atividades produtivas, ainda que em um grau de especialização espacial bastante mais acentuado.

Sandra Lencioni analisou as diferentes formas de reapropriação desses espaços por parte dos agentes econômicos, seja como centro de gestão seja como base de indústrias de alta tecnologia e, com isso, a instituição da "metrópole como sobrevida do capitalismo" (LENCIONI, 2008). Assim, a metrópole segue sendo o espaço privilegiado para o movimento geral de reprodução do capital, embora vários autores tenham delineado novas denominações que tentam requalificar esse espaço como megacidades (BORJA e CASTELLS, 1996), megalópole (LEFEBVRE,

\footnotetext{
${ }^{1}$ Como se sabe, esse modelo é resultante da organização mais racional das estruturas produtivas no início do século $X X$, que conjugam linhas de montagem, alto grau de especialização da força de trabalho e controle intelectual da produção. Tal modelo foi assim denominado por ter tido como seu principal difusor o líder do setor automobilístico da época, Henry Ford.
} 
1978, 1976), cidades-região (SCOTT, 1998), megarregião (SASSEM, 2007), exópoles (SOJA, 1993, 1994) e outras.

Com este texto, pretendemos apresentar alguns referenciais mais amplos acerca desse processo e analisar aspectos importantes dessa reapropriação no espaço fluminense, pois trata-se de uma metrópole imersa em obras de infraestrutura e de projetos que tentam recuperá-la como centro gestor da economia fluminense e requalificar seus espaços de atividades industriais. Resta saber como encontrar, em meio a essas mudanças e novos usos do território, os projetos de valorização dos sujeitos sociais que a habitam e se há a construção de canais participativos para administrar essas transformações.

\section{Uma Nova Perspectiva Analítica para a Metrópole}

As áreas metropolitanas se tornaram expressivas, em todo o mundo, no decorrer da década de 1960, como resultado de uma intensificação das estruturas e da capacidade de produção baseada no modelo fordista. No pós-Segunda Guerra Mundial, a consolidação e o fortalecimento da economia de mercado, bem como a expansão das redes de empresas em todo o mundo, sob forte influência dos investimentos estatais, e uma significativa expansão dos mercados de consumo fizeram com que a urbanização em todo o mundo se tornasse um processo irreversível.

Surgem, nesse momento, as primeiras discussões acerca do fenômeno de expansão urbana e da formação das áreas metropolitanas. Inicialmente, tais discussões abordam os efeitos da concentração de investimentos nos núcleos metropolitanos, em face, por um lado, da condição de liderança das metrópoles como centros de atividades econômicas, mas, por outro, também da sua posição como centro cultural, de comunicação, de inovação e de produção de conhecimento. No mesmo processo, verifica-se o transbordamento das atividades residenciais e industriais para cidades contíguas e próximas, formando as bases para a aglomeração urbana que se intensifica em torno do núcleo. O processo de metropolização, portanto, é fortemente influenciado pela polarização do núcleo, formando uma estrutura mononuclear.

Produz-se então um âmbito de organização do território não-previsto nas formas institucionais clássicas, que variam de país para país, mas que, em geral, definem-se pela presença de um nível nacional de governo, interrelacionado hierarquicamente em níveis subnacionais, relativos às escalas político-administrativas das regiões (equivalentes aos estados no Brasil), das províncias, das comarcas e dos municípios (IERMB, 2009).

Por sua constituição histórica e por definição clássica, as áreas metropolitanas constituem áreas plurimunicipais e, por isso, exigem uma definição clara acerca da gestão desses territórios, na medida em que nenhum município isoladamente pode responder aos fenômenos metropolitanos, cuja forma de manifestação se dá sempre em uma escala mais ampla. Isso constitui certamente no maior desafio a ser enfrentado no debate da questão metropolitana, pois "é necessária a coordenação dos diferentes poderes municipais ou a existência de uma estrutura política de nível superior para tratar da complexidade das aglomerações urbanas" (IERMB, 2009, p. 14). 
O enfrentamento dessa limitação nos países europeus é tão grande e complexo quanto nas metrópoles brasileiras, mas em todos os países europeus sempre há uma forma institucional de agregação e gestão desses espaços, de maneira que:

algumas instituições são de caráter local e operam sobre um território metropolitano específico; outras cobrem um território substancialmente mais extenso, fruto de uma subdivisão territorial de Estado realizada à margem das dinâmicas metropolitanas. Também se pode encontrar o caso de níveis institucionais de Estado, que podem ser regiões ou províncias, coincidindo com o território metropolitano. Nesse caso, as instituições podem exercer realmente um governo metropolitano (IERMB, 2009, p. 17).

Observamos assim que não existem propriamente "governos metropolitanos" para gerir e administrar esses espaços. Apenas para confirmar a regra, encontramos duas exceções, recém-criadas, que têm tido êxito na gestão de suas respectivas aglomerações urbanas: a Greater London Authority, criada em 2000, e algumas Communautés Urbaines de France, que administram áreas metropolitanas fora da região de île de France - cujo núcleo central é a aglomeração de Paris. Todavia, mesmo sem a existência generalizada de níveis de governo para gerir esses espaços, observa-se algum nível oficial de institucionalidade, sem o qual a metrópole se torna ingovernável.

Nesse ponto, voltamos a considerar a experiência brasileira e a estrutura administrativa municipal que organiza a gestão territorial em nossas metrópoles. No Brasil, somos herdeiros de uma tradição administrativa europeia, na qual as formações municipais historicamente se fundam nas bases feudais. Por aqui, o municipalismo é fortemente marcado pelo coronelismo que, advindo de uma tradição de controle territorial - que assumiu feições agudas no nordeste no período escravocrata -, apresenta-se como modelo nacional de gestão local, em que se advoga uma autonomia absoluta - autonomia não-baseada em uma tradição cultural de todo o povo, mas sim como expressão do controle político das classes dominantes.

Essa é uma discussão sobre as bases do municipalismo brasileiro que, no campo do planejamento e do urbanismo, não avançou muito entre nós, por uma espécie de reconhecimento do fato consumado: não há o que fazer. Também há, por outro lado, uma defesa explícita desse modelo por muitos analistas, devido à crença de que o município é o espaço mais adequado para o exercício da democracia, pois aproxima administradores e munícipes, sociedade civil e Estado, de forma que esse modelo de administração territorial deve ser defendido e preservado. Tais abordagens e concepções, no entanto, calam-se diante dos problemas gerados para o enfrentamento dos problemas sociais e a ausência de mecanismos de gestão solidária e democrática das cidades. Não enfrentam, analiticamente, as bases sobre as quais esse modelo se estrutura e consideram que os desmandos e domínios das classes dominantes podem ser superados pelas forças e mecanismos de participações populares. 
Deixemos de lado, por enquanto, essa questão para podermos centrar no ponto que nos perece mais importante em nossa análise: a autonomia municipal e sobretudo a recusa das administrações municipais em reconhecer qualquer nível de governo ou instituição que esteja "acima" de seu poder. Essa recusa limita, ou melhor, impede qualquer possibilidade de uma gestão democrática e eficiente do espaço metropolitano, que só poderá ser alcançada por meio da constituição de níveis de gestão compartilhada das áreas metropolitanas.

Como reverso da mesma moeda, há igualmente a recusa na relação para "baixo", ou seja, relativa à promoção de formas de gestão participativa e democrática a partir de instâncias e mecanismos que envolvam toda a população e instituições locais. Nesse aspecto, diríamos que é intensa a recusa à aceitação de que a política participativa é o amalgama fundamental para o êxito na administração pública que vise ao bem estar de toda a população.

Assim, ao contrário de outros espaços metropolitanos nos países mais industrializados - em que o ordenamento político-territorial prevê governos de regiões autônomas, de províncias e outras formas regionais de governos e que, por isso, são reconhecidos pelas instituições municipais como legítimas para coordenar ações e organismos de gestão dos espaços metropolitanos -, a estrutura administrativa brasileira reconhece os municípios como ente federativo e lhes atribui um controle quase absoluto sobre seu território. Com isso, no Brasil inexistem ou são absolutamente inoperantes as instituições de gestão plurimunicipais, em geral organizadas na forma de consórcios para a gestão de alguns poucos serviços de interesse comum ou para tratar de questões ambientais associadas às bacias hidrográficas.

Esse é o motivo pelo qual as entidades metropolitanas, criadas no ato da institucionalização das nove primeiras regiões metropolitanas no Brasil, em 1974, não tenham tido nenhum apoio e reconhecimento por parte da maioria dos municípios metropolitanos. No caso do Rio de Janeiro, a Lei Federal Complementar $\mathrm{n}$. 20, de $1^{\circ}$ de julho de 1974, ao mesmo tempo em que institui formalmente a Região Metropolitana do Rio de Janeiro, unifica também os antigos Estados da Guanabara e do Rio de Janeiro, gerando conflitos adicionais ao próprio projeto, uma vez que acaba por estimular disputas locais e de interesses específicos das elites dirigentes contrárias ao processo de fusão. O ato cria também a Fundação para o Desenvolvimento da Região Metropolitana do Rio de Janeiro (FUNDREM), instituição que deveria ter tido amplo respaldo para propiciar e garantir a gestão compartilhada das políticas públicas em toda a área metropolitana.

Inicialmente, a FUNDREM atuava como assessoria técnica às prefeituras, principalmente na elaboração de planos diretores e na tentativa de gestão dos serviços de interesses comuns, em particular a coleta e destinação do lixo. Mas sua importância como órgão de planejamento foi sendo esvaziada por interesses coorporativos dos sucessivos governos estaduais e principalmente pela desativação dos fundos federais de desenvolvimento urbano, no início dos anos 1980, até a completa extinção desses fundos em 1983. Sem recursos para estimular as demandas que a mantivessem com visibilidade, a FUNDREM foi extinta em 1989. Evidentemente, essa breve existência demonstra que "o fato metropolitano deixou de ser percebido como uma realidade substantiva a exigir políticas adequadas aos seus 
elementos socioeconômicos concretos" (FONTES e ARAÚJO, 1995, p. 398). Isso evidencia o completo despreparo institucional por parte do Estado e das forças políticas nacionais para perceber a região metropolitana como território portador de estrutura, conexões e dinâmicas próprias que exigem, para dar conta de toda a sua potencialidade, políticas claras de gestão compartilhada e não o privilegiamento de políticas "autônomas" municipais, uma vez que se trata de um espaço complexo.

A recusa de reconhecimento de instituições com atuação supramunicipal permanece nos processos recentes de instituição das novas regiões metropolitanas e aglomerações metropolitanas, delineadas pelos legislativos estaduais, conforme autorização para esse fim concedida pela Constituição Federal de 1988.

\section{A Degradação da Velha e Reconfiguração da Nova Metrópole Fluminense}

A dinâmica econômica metropolitana no Rio de Janeiro é outra completamente diferente da que conhecemos até os últimos anos do século XX. Até o final da década de 1990, o esvaziamento econômico da cidade do Rio de Janeiro refletia intensamente no restante do espaço metropolitano, em face da ainda forte dependência do núcleo sobre toda a área e região metropolitana. Hoje, a economia baseada nas atividades extrativistas no norte do estado, nos novos padrões tecnológicos do setor metal mecânico da região do Médio Vale do Paraíba e sobretudo, nas políticas de investimento nos setores de logísticas, petroquímica e siderurgia pelo Estado e setores privados, promovem uma esplêndida requalificação na metrópole fluminense baseada em novos setores e recursos originados fora da metrópole.

Essas transformações precisam ser compreendidas a partir das mudanças no cenário econômico, social e político, para que possamos trabalhar as relações sociais e as novas perspectivas de uso desse território. Isso é importante, pois a degradação vista no decorrer das décadas de 1980 e 1990 é, em grande medida, decorrente de incapacidade de gestão da economia e do território no estado.

A década de 1980 foi considerada perdida pelos analistas econômicos, mas a economia metropolitana fluminense apresentou níveis de deterioração maiores do que todas as demais metrópoles brasileiras. Os dados de empregos formais no Brasil deixam à mostra a decadência do estado do Rio de Janeiro frente às demais unidades da federação. As taxas de crescimento do pessoal ocupado, tendo como referência os intervalos quinquenais, a partir de 1985, e o ano de 2006, mostram que o estado do Rio de Janeiro foi o que teve o menor ín-dice de crescimento em todos os quinquênios (Tabela 1).

Coincidentemente, no período coberto pela tabela, verificamos uma sucessão de governos absolutamente incapazes de promover um amplo diálogo e mobilização das forças produtivas no estado para um projeto de crescimento econômico e desenvolvimento social, com ampla participação popular: Moreira Franco (19869); segundo governo Brizola (1990-3); Marcelo Alencar (1994-7); Anthony Garotinho (1998-2001); e, por fim, o mais trágico de todos, Rosinha Garotinho (2002-5). Em todos esses anos, nenhum projeto de investimento em infraestrutura e logística industrial de importância estratégica pode ser identificado.

Na cidade do Rio de Janeiro, a ingovernabilidade se instala com a ascensão de Cesar Maia e seu projeto, em 1993, que se prolongou por intermináveis dezesseis 
\} Em Defesa do Território: Expansão Metropolitana e Lutas Sociais - OLIVEIRA, J. G. F. \}

anos. Acreditando na inexorabilidade da globalização e no city marketing como estratégia de gestão, lançou a cidade em uma aventura para sua conversão em centro regional de comunicação e gestão informacional de toda a América Latina, tendo por base o projeto do teleporto - um projeto de revitalização e transformação de todo o centro e zona portuária da cidade com infraestruturas e equipamentos imo-biliários e de comunicação -, que contribuiria para a transformação da cidade do Rio de Janeiro de uma economia industrial para um centro avançado de serviço e de turismo. Depois de inúmeros projetos fracassados, como o Rio-cidade ou o Favela-bairro - pois foram intervenções pontuais que não alteraram a estrutura urbanística e social das áreas atingidas -, essa aventura terminou com o quase estúpido finan-ciamento pelos cofres municipais do museu Guggenheim, mas não logrou escapar da construção da mais absurda obra de equipamento cultural da cidade, a Cidade da Música, no bairro da Barra da Tijuca.

Tabela 1

Taxa de crescimento do número de Pessoal Ocupado por estado, 1985 - 2006 - RAIS

\begin{tabular}{l|r|r|r|r|r}
\hline \multicolumn{1}{c|}{ Estados } & Cresc 85 06 & Cresc 90 06 & Cresc 95 06 & \multicolumn{1}{c}{ Cresc 00 06 } & \multicolumn{1}{c}{ Cresc 02 06 } \\
\hline Média Região Norte & 160,76 & 115,11 & 96,90 & 63,76 & 38,22 \\
\hline Média Região Nordeste & 97,35 & 68,51 & 60,50 & 41,40 & 27,30 \\
\hline Minas Gerais & 103,92 & 70,51 & 53,68 & 33,55 & 22,90 \\
\hline Espírito Santo & 123,37 & 85,00 & 68,20 & 49,96 & 28,24 \\
\hline Rio de Janeiro & $\mathbf{2 6 , 1 7}$ & $\mathbf{1 8 , 8 3}$ & $\mathbf{2 5 , 5 0}$ & $\mathbf{2 4 , 1 2}$ & $\mathbf{1 5 , 4 4}$ \\
\hline São Pa ulo & 52,69 & 35,12 & 33,82 & 28,15 & 19,83 \\
\hline Paraná & 104,47 & $\mathbf{7 4 , 4 6}$ & 53,94 & 36,16 & 24,20 \\
\hline Santa Catarina & 115,01 & 85,54 & 75,90 & 48,29 & 29,37 \\
\hline Rio Grande do Sul & 44,12 & 31,19 & 34,21 & 22,55 & 14,47 \\
\hline Mato Grosso do Sul & 150,72 & 109,94 & 71,83 & 46,41 & 25,48 \\
\hline Mato Grosso & 265,90 & 160,43 & 122,91 & 64,20 & 36,65 \\
\hline Goi ás & 149,19 & 128,37 & 94,28 & 49,54 & 27,05 \\
\hline Distrito Federal & 94,62 & 69,37 & 45,74 & 12,87 & 12,70 \\
\hline Total & $\mathbf{7 1 , 5 5}$ & $\mathbf{5 1 , 5 4}$ & $\mathbf{4 7 , 9 9}$ & $\mathbf{3 4 , 0 3}$ & $\mathbf{2 2 , 5 6}$ \\
\hline
\end{tabular}

Fonte RAIS - $1985-2006$

Esse quadro da política fluminense, ainda que resumido, mostra com absoluta correção que não se trata de uma, mas de duas décadas perdidas no estado do Rio de Janeiro, se o ponto de vista for o da produção econômica e da gestão política da economia. A recuperação econômica do estado e, consequentemente, a criação de alguma esperança de melhorar as condições de gestão administrativa do território, começam, no decorrer da década de 1990, pela força das atividades extrativistas na região norte e pela atração de empresas que utilizam equipamentos de alta tecnologia na região sul, particularmente a indústria automobilística e de autopeças, atraídas para a região no processo de reestruturação produtiva do setor metal mecânico do Vale do Paraíba.

A área metropolitana, até o final dessa década, não apresentava nenhuma perspectiva de recuperação. Todas as expectativas de recuperação econômica eram 
lançadas no polo gás-químico, como um setor impulsionador do setor petroquímico, mas nada era produzido em termos de logística que propiciasse as condições básicas necessárias para o crescimento econômico. Com isso, a lista de perdas de investimentos no espaço metropolitano aumentava seguidamente: falência total do setor naval (década de 1980); suspensão da construção do polo petroquímico de Itaguaí (1987); deslocamento das empresas de informática instaladas no Rio de Janeiro para São Paulo (década 1980); pouca utilização do gás natural em seu desenvolvimento (início década 1990); fraco desempenho do projeto Rio Polímeros, responsável pelo polo gás-químico; poucas atividades e nenhum investimento no porto de Itaguaí (Itaguaí); incapacidade de levar avante perspectivas apontadas no Plano Estratégico da Cidade do Rio de Janeiro, coordenado por Carlos Lessa; e outras derrotas econômicas.

Tudo isso é muito estranho em uma unidade da federação com imensa massa crítica, grandes instituições de ensino e pesquisa, força de trabalho muitíssimo qualificada e importantes estruturas logísticas, cujo aproveitamento necessitava de ajustes e investimentos modernizadores, como nos aeroportos, portos e rodovias. Assim, defendemos que o esvaziamento econômico e o acirramento da degradação e exclusão social no estado não são somente decorrentes das conjunturas econômicas internacionais, efeitos da globalização e outras formas de integração funcional das estruturas produtivas, mas, no nosso caso, da ordem próxima, ou seja, da capacidade de gestão e do ordenamento político-territorial do estado do Rio de Janeiro.

\section{Mudanças no Ordenamento Político-Econômico-Social do Território e Relações Sociais na Metrópole Fluminense}

As transformações recentes na estrutura produtiva e econômica do estado do Rio de Janeiro, onde as atividades no interior se tornaram importantes e até mesmo decisivas, fizeram com que a metrópole fosse novamente acionada não só como centro gestor, em função de todas as atividades que ocorrem na metrópole como as financeiras, de serviços especializados, centros de ensino e pesquisas, culturais etc. -, mas também como centro industrial renovado, abrigando empresas e setores que utilizam alta tecnologia.

Esse fato é um primeiro indício de que a recuperação da economia do estado e de seu principal espaço metropolitano passa pela diversidade de investimentos e atividades, não devendo se restringir à velha e limitada "vocação" da cidade do Rio de Janeiro - como se a cidade do Rio de Janeiro fosse o único espaço produtivo do estado - de turismo e serviços de alta densidade técnica. O sonho acabou. Defender a metrópole fluminense apenas pelo ângulo de produção de infraestrutura de serviços destinados ao turismo e serviços altamente especializados é uma forma anacrônica de mostrar a não-aceitação do fato de que a cidade do Rio de Janeiro é um município que integra um conjunto maior do território e da metrópole fluminense.

No atual contexto, o dinamismo econômico e as perspectivas de ampliação das atividades econômicas na metrópole fluminense mostram-se diretamente vinculados à economia do interior. O principal setor que passa por uma reestruturação no espaço metropolitano é inegavelmente o naval, em função do volume de encomendas realizadas por empresas ligadas ao setor extrativista do petróleo e gás, 
\} Em Defesa do Território: Expansão Metropolitana e Lutas Sociais - OLIVEIRA, J. G. F. \}

determinado pela obrigatoriedade de que $60 \%$ da construção do navio ou equipamento seja realizado no território nacional. Esse setor fortalece a cadeia produtiva do setor metal-mecânico no estado e, como a maior parte da indústria naval está localizada na metrópole, esse fato beneficia o renascimento desse setor no estado.

Também de forma vinculada ao extrativismo do petróleo e gás, a Petrobras iniciou a construção do Complexo Petroquímico do Rio de Janeiro (Comperj), no município de Itaboraí, que é metropolitano, e desencadeou com isso um processo imenso de mobilização social e de novas dinâmicas territoriais no leste da Região Metropolitana do Rio de Janeiro (RMRJ).

Vamos por partes. Trata-se de um investimento da ordem de 8 bilhões de dólares, para a construção de uma refinaria especial que beneficie o óleo extraído na Bacia de Campos. Essa refinaria beneficiará o petróleo vindo da Bacia de Campos e produzirá uma matéria-prima para empresas petroquímicas, chamadas de segunda geração, pois utilizará essa matéria-prima para produzir plásticos. Esse material será então destinado a empresas de terceira geração, que produzirão, a princípio, utensílios e bolsas de plástico destinadas ao consumo. Trata-se portanto de uma cadeia produtiva que poderá mobilizar muitas pessoas e recursos.

A instalação do complexo mobiliza outro conjunto de investimentos, agora de logística e infraestrutura viária para permitir o desenvolvimento do projeto petroquímico. No próprio município de Itaboraí, a instalação de um imenso complexo de tratamento de resíduos sólidos, com vista ao atendimento do esperado aumento da demanda, já antecipa alguns investimentos que serão realizados. Como o Comperj é uma atividade que utiliza tecnologia de última geração e necessita de suporte logístico para importação e exportação de equipamentos e produtos, o Estado privilegia como investimentos paralelos a ampliação do porto de Itaguaí e, para garantir o acesso ao porto, a construção de uma rodovia que receberá a denominação de Arco Rodoviário - pois terá a forma de um meio circulo - que ligará a BR 101 norte, no município de Itaboraí, à própria BR 101 sul, no município de Itaguaí, próximo à estrada do porto. Tratase de uma rodovia que contorna toda a Baía de Guanabara, interligando os municípios da franja externa da metrópole e superando a limitada condição de circulação entre o leste e o oeste da área metropolitana, cuja ligação dependia da circulação pela ponte Rio-Niterói e pela Avenida Brasil. A circulação e a integração econômica entre os municípios metropolitanos eram assim inviabilizados economicamente devido à saturação e restrição de horários para circular nessas vias. Agora, com a construção do Arco Rodoviário, além de uma maior e muito importante integração entre esses municípios, existe uma forte expectativa de que as indústrias de terceira geração do Comperj se distribuam ao longo dessa estrada.

A atração de novos investimentos industriais para a área metropolitana do Rio de Janeiro já está ocorrendo e, por efeito da localização do novo porto e da rodovia, novas indústrias estão se localizando novamente no Rio de Janeiro. O maior investimento está ocorrendo próximo ao porto. Surpreendentemente, o consórcio formado pela Mineradora Vale e o grupo ThyssenKrupp construiu a segunda maior 
siderúrgica do estado no extremo oeste da cidade do Rio de Janeiro, a Companhia Siderúrgica do Atlântico (CSA), demonstrando que há sim perspectivas industriais no projeto de crescimento econômico e desenvolvimento social na área metropolitana do Rio de Janeiro e, em especial, na capital do estado. Também merece destaque a indústria da Petroquisa, subsidiária da Petrobras, que seria instalada em São Paulo, mas foi transferida para o município de Seropédica, onde se localiza a Universidade Federal Rural do Rio de Janeiro.

Esses investimentos promovem uma integração territorial importante no estado. Eles produzem uma rede técnica integrada, de extremo valor agregado. No norte do estado, a duplicação da BR 101 e a construção de um oleoduto, ao lado do gasoduto já existente, promovem uma rede técnica que potencializa toda a infraestrutura e a logística já existentes nos municípios de Campos, Macaé e, mais recentemente, São João da Barra, a partir da instalação do complexo portuário do Açu nesse município. Essa rede técnica será potencializada pelo uso do traçado do Arco Rodoviário e também contornará toda a Baía de Guanabara, integrando, como já foi dito, os sete municípios externos na área metropolitana do Rio de Janeiro, não apenas do ponto de vista viário, mas também do ponto de vista de infraestrutura produtiva. A partir do município de Itaguaí, onde chega a nova rodovia, uma rede ferroviária se encarregará de integrar a área do porto ao sul fluminense, consolidando o polo siderúrgico de Itaguaí e Volta Redonda.

A área metropolitana do Rio de Janeiro e a cidade do Rio de Janeiro portanto reassumem um papel importante na organização do território fluminense e, nesse processo, criam novas perspectivas de gestão e expansão física da metrópole. É importante frisar, porém, que falamos em crescimento econômico, que não significa desenvolvimento social. Esse então se torna o desafio a ser enfrentado. Como fazer para que o resultado desse processo seja apropriado socialmente pelo conjunto da população? Como fazer para que esses investimentos sejam as bases para lograrmos o desenvolvimento e não, ao contrário, promover a degradação social e ambiental?

O conceito de desenvolvimento portanto precisa ser mais uma vez comentado. Reportamo-nos, neste caso, a dois autores que o definem como uma conjugação dos fatores, de forma que o desenvolvimento seja considerado, numa perspectiva macroeconômica, o "aumento persistente da produtividade do fator trabalho e suas repercussões na organização da produção e na forma como se distribui e utiliza o produto social" (FURTADO, 2000, p. 15). Nessa concepção, ocorre a indissociabilidade entre a produtividade do fator trabalho e a distribuição da riqueza socialmente produzida. Cândido Grzybowski, numa perspectiva mais sociológica, delineia o conceito como "(antes e acima de tudo) transformação de estruturas, relações e processos econômicos, políticos e culturais, para que a sociedade tenha novas bases de vida" (GRZYBOWSKI, 2006, p. 7).

\section{O Território "Ativo" nas Lutas Sociais}

É fundamental, neste debate, ressaltar o papel ativo do território nesse processo. Milton Santos, em um artigo denominado "O retorno do território", procura demonstrar a importância de se reencontrar o conceito tendo em consideração que 
\} Em Defesa do Território: Expansão Metropolitana e Lutas Sociais - OLIVEIRA, J. G. F. \}

"é o uso do território, e não o território em si mesmo, que faz dele objeto da análise social" (SANTOS, 1996, p.15), destacando a necessidade de recuperarmos, analiticamente, o papel ativo do território. Disso também resulta a necessidade de um novo olhar sobre as relações de poder no território. Em trabalho recente, defendemos que a produção do espaço social (e isso inclui diretamente a organização do território) se tornou um campo de lutas sociais, pois "o espaço geográfico, agora mais do que antes, é um elemento estratégico para as empresas e para o processo de reprodução ampliada do capital" (OLIVEIRA, 2008, p. 28). Logo, o território, a forma como se administra e se organiza o território, sempre foi, mas agora não há mais como esconder, um elemento estratégico para a reprodução do capital. Por isso, torna-se também um elemento a mais de disputa entre as classes populares e dominantes. Sendo assim, compreender a amplitude da questão e organizar formas de lutar para impor limites ao uso do território e com isso negociar os direitos sociais se tornou parte central de uma estratégia de conquista do controle social do território.

As transformações da metrópole favorecem essas lutas. A organização e o ordenamento do território em tempos de globalização deixam transparecer mais intensamente os usos instrumentais que o capital impõe aos lugares. É mais o uso e menos o domínio territorial ${ }^{2}$ que se evidencia nesta fase da acumulação capitalista, face ao predomínio dos fluxos, que atravessam e reconfiguram os territórios, delineando um novo padrão de dominação e reorganização do espaço social produtivo. Esse processo, caso não seja enfrentado como um novo campo de lutas sociais, poderá configurar o que foi denominado por Algebaile como uma "expansão para mais", em sentido espacial, estruturalmente conjugada a uma expansão "para menos", em sentido social (ALGEBAILE, 2009).

Propomos essa linha de raciocínio, pois o processo em curso na metrópole fluminense tem gerado uma ampla reconfiguração do espaço metropolitano, cujos novos usos do território devem ser "negociados". Em primeiro lugar, destacamos que esses investimentos estão promovendo uma redefinição da área metropolitana, incorporando novas cidades ao tecido urbano historicamente constituído e ampliando o alcance regional da metrópole. Consideramos área metropolitana o território urbano contíguo à cidade do Rio de Janeiro, núcleo da metrópole, e região metropolitana o recorte delineado institucionalmente, cuja agregação não necessariamente inclui áreas urbanas contíguas. Essa delimitação ampla obedece a critérios de fluxos comerciais e de deslocamentos populacionais para o trabalho, bem como de uma possível gestão conjunta de serviços de interesses comuns, que orientaram a institucionalização desses espaços em 1974.

$\mathrm{Na}$ configuração que se delineia atualmente, a metrópole fluminense incorpora inúmeros municípios a leste e a oeste da Baía de Guanabara. Na parte leste, além dos que já compõem a RMRJ, como Guapimirim, Itaboraí, Magé, Niterói, São Gonçalo e Tanguá, que agora tendem a uma maior integração do tecido urbano, outros são agregados e passam a compor a metrópole expandida, como Maricá município que foi retirado da RMRJ, em 2000, mas que parece-nos reintegra-se por força da dinâmica imobiliária atual -, Rio Bonito, Cachoeiras de Macacu, Silva Jardim e Casimiro de Abreu. Esses municípios, que antes não tinham relações ad- 
ministrativas de compartilhamento de gestão de serviços ou outros tipos de associação administrativa, agora se consorciaram para discutir e defender seus respectivos territórios, em face da instalação do Comperj em Itaboraí.

O Consórcio Intermunicipal para o Desenvolvimento do Leste Metropolitano (Comleste) foi formado após o anúncio da área que será impactada pelas obras e atividades do Comperj. É evidente que há destacadamente um interesse econômico de buscar defender a ampliação da arrecadação de cada município e do recebimento dos possíveis royalties que serão devidos, por se tratar de atividades com petróleo e gás. Mas há ainda outros aspectos que são de grande importância para defender o território afetado pelo empreendimento, pois o uso desse território pressupõe a utilização de recursos físicos e humanos, bem como possíveis degradações sociais e ambientais. Merecem destaque, neste caso, as questões relativas à poluição das águas da Baía de Guanabara, às limitadas fontes de água e às formas de captação para o Comperj, aos dejetos industriais decorrentes desse tipo de atividade, aos impactos sociais advindos do poder de atração populacional para a região, à necessidade de ampliação dos serviços e da infraestrutura urbana na região etc.

A defesa desse território passa, principalmente, pelo controle dos usos. Se às empresas interessa instalar-se e usar esse território, elas deverão tomar todas as precauções e realizar todos os investimentos sociais e ambientais necessários para preservar o território e garantir os benefícios sociais com anterioridade. Reafirmamos essa questão, pois o que ocorre atualmente é o inverso. Acredita-se que, com o início das operações, o aumento da arrecadação possibilitará os investimentos sociais necessários e as correções dos estragos ambientais. Essa concepção é a mais enganosa possível, pois as ações preventivas têm muito maior eficácia e garantia do que as corretivas.

Um grande exemplo disso pode ser visto na experiência de gestão dos recursos advindos dos royalties na região produtora de petróleo e gás, no norte do estado. Os municípios do norte fluminense, que são os que recebem os maiores valores de royalties devidos pela Petrobras, como é o caso de Campos e Macaé, mostram-se incapazes e, por que não dizer, incompetentes para reverterem o quadro de degradação social e ambiental nos municípios que compõem a Bacia de Campos. Nesses municípios, também existe um consórcio municipal, a Organização dos Municípios Produtores de Petróleo (OMPETRO), que reúne a cada dois meses todos os prefeitos dos nove municípios produtores de petróleo do norte fluminense. $\mathrm{Na}$ pauta dessas reuniões não constam assuntos sociais, de produção de infraestrutura econômica, de organização social ou cidadania - apenas a arrecadação dos royalties. Essa organização, portanto, é incapaz de discutir os investimentos sociais necessários para reverter o quadro de pobreza que ainda subsiste na região.

Assim, defendemos que o Conleste deve ser tomado pelas forças sociais e pelos movimentos populares, para que este deixe de ser um fórum de prefeitos e assuma a condição de um sujeito social em defesa do território e não da arrecadação.

O mesmo se repete nas demais partes do território metropolitano. No oeste, o município de Itaguaí, que foi excluído da RMRJ em 2001, volta a participar ativamente da economia metropolitana com a ampliação do porto e, por efeito direto disso, atraindo indústrias de grande porte e se tornando o centro do polo siderúrgico constituído no sul fluminense. 
Inicialmente, a ampliação do porto de Itaguaí, situado na Baía de Sepetiba, era uma demanda para substituir o porto do Rio de Janeiro, localizado na sofrida, poluída e assoreada Baía da Guanabara. Com as novas tecnologias de transportes e com o porte dos atuais navios, com a proliferação do uso dos contêineres e principalmente pela enorme dificuldade de instalações de logística e circulação no porto do Rio, as condições de funcionamento no centro da cidade do Rio de Janeiro tornaram-no absolutamente antieconômico. A transferência das atividades para a Baía de Sepetiba foi uma demanda real, mas, por outro lado, agora é uma ameaça de destruição dessa outra baía.

Para além da ampliação do porto de Itaguaí pelo governo federal, outros investidores privados estão também transferindo suas bases portuárias para a Baía de Sepetiba. A CSA já criou seu porto particular, construindo um acesso de três quilômetros de píer para chegar ao seu ancoradouro. Outros quatro projetos de portos privados estão sendo licenciados pelo governo do estado para instalação nessa baía.

Os ganhos sociais de todos esses investimentos são incertos e até mesmo limitados em face do uso de equipamentos de alta tecnologia nesses empreendimentos, que, consequentemente, não terão como resultado a geração de um grande número de empregos, bem como de rendas. Mas os efeitos de destruição do meio ambiente e de degradação da Baía de Sepetiba já são sentidos e percebidos a olhos nus. Dragagem dos canais de acesso às áreas dos portos em construção; assoreamento do fundo da baía, fechando o canal da Restinga de Marambaia; presença de óleo nas águas antes límpidas; presença constante de doze a quinze navios de transportes de minérios e carvão, de contêineres, de automóveis e outros nas águas da baía são os sinais evidentes de um futuro social e ambientalmente incerto.

Nessa parte da área metropolitana, as lutas sociais e organizações populares são menos presentes, mas a proximidade com os municípios da Baixada Fluminense já permite uma mobilização das forças políticas e populares em defesa do maior controle social desses empreendimentos e do meio ambiente.

Assim, mesmo sem nos aprofundarmos na análise de formas mais concretas de mudanças no território e nos efeitos sociais que esses empreendimentos têm gerado, fica claro que esse é um novo campo de lutas das forças populares na metrópole. Isso porque o capital agora busca dirigir e influenciar o Estado, em seus diferentes níveis de governo, para produzir infraestruturas específicas para seus negócios. E os interesses das classes trabalhadoras, quais são? Como definir formas de participação e retomar a defesa dos orçamentos participativos juntos às administrações públicas? Como restringir os usos especulativos por parte do capital das áreas já ocupadas pela população?

Sem querer entrar em análises de caso, vale a pena mencionar a vitória dos pescadores de Maricá, que conseguiram impedir a mudança da legislação estadual que visava a ampliar de quinze para $45 \%$ a área edificável da APA do município. Com isso, limitou-se bastante o interesse de empresários espanhóis que compraram a área e queriam fechar a APA para construção imobiliária. Cito esse exemplo para registrar que, como nos ensinou Milton Santos, o território não é um espaço liso, pois nele há regras sociais e culturais que necessitam ser respeitados e sabemos, 
duramente, que esse respeito não resulta de boa vontade, mas de relações políticas capazes de fomentar o reconhecimento da questão social em jogo.

\section{Considerações Finais}

Pensar as lutas sociais também no campo de disputas pelo território é uma possibilidade importante a ser considerada. O capital há muito alterou sua estratégia de relacionamento com as forças produtivas locais, particularmente com as que administram os territórios, pois seu interesse estratégico é cada vez mais local. Antes, ao capital importavam os financiamentos e acordos realizados em escala nacional, com os governos centrais. Hoje, seus interesses e estratégias são cada vez mais locais, sob a égide de programas de "desenvolvimento local", de "planejamento estratégico", segundo "arranjos produtivos locais" ou "desenvolvimento endógeno".

Estrategicamente, os agentes do capital anteciparam-se às mudanças decorrentes da reestruturação produtiva, instituída como forma de recuperação da crise dos anos 1970, produzindo uma nova forma de relacionamento com as forças produtivas locais: reconhecem os direitos sociais e a necessidade de investimentos públicos para garantir esses direitos, mas agora corresponsabilizando os próprios movimentos pela obtenção das condições para produzir seu atendimento. Harvey mostra isso com muita exatidão quando discute que planejamento estratégico, coesão social e desenvolvimento local são as palavras-chave do capital, já que, no fundo, são termos que operam a "mágica" de transferir para as administrações municipais a responsabilidade sobre os efeitos das novas atividades produtivas, fazendoas assumir subordinadamente o papel de "empreendedores" do desenvolvimento .

Diante do reconhecimento desse novo cenário e dos novos padrões do enfrentamento e disputas entre as classes exploradas e as dominantes, emerge, portanto, um papel importante a ser assumido pelos movimentos populares e pelas forças sociais mais avançadas - o de defesa do território. Defender o uso coletivo e não-predatório dos recursos naturais e do patrimônio cultural e ambiental, a tributação justa sobre as atividades produtivas, o controle político e a defesa da gestão participativa dos municípios, a gestão institucional compartilhada do território metropolitano - enfim, a gestão do território como um campo de lutas sociais.

Nossa intenção nesse texto foi ressaltar isso: o fato de que há um intenso dinamismo na organização dos territórios, particularmente nas áreas metropolitanas, que exigem de nós a produção de novas estratégias de enfrentamento e fortalecimento dos movimentos sociais, ampliando o campo das lutas por direitos sociais para também a gestão social do território. 


\section{Referências Bibliográficas:}

ALGEBAILE, Eveline. Escola pública e pobreza no Brasil: a ampliação para menos. Rio de Janeiro: Editora Lamparina, 2009.

. Expansão metropolitana, erosão da esfera pública e novas exigências

sociais de governabilidade. Revista Eletrônica Scripta Nova, vol. XI, n. 245.

Barcelona: Universidade de Barcelona, 2007.

BENKO, George. Economia, espaço e globalização na aurora do século XXI. São Paulo: Editora Hucitec, 1996.

BORJA, Jordi e CASTELLS, Manuel. Local e global: la gestión de las ciudades en la era de la información. Barcelona: Ajuntament de Barcelona/ Habitat II, 1996. CAPEL, Horacio. Capitalismo y morfologia urbana em Espana. Barcelona: Amélia Romero Editor, 1983.

. El debate sobre la construcción de la ciudad y el llamado modelo Barcelona. Revista Scripta Nova, Revista Electrónica de Geografía y Ciencias Sociales (ISSN: 1138-9788), vol. XI, n. 233, 15 de fevereiro. Barcelona: Universidade de Barcelona, 2007.

FONTES, A. e ARAÚJO, V. Gestão metropolitana, fragmentação política e processo de subregionalização: as tendências político-institucionais na questão metropolitana do Estado do Rio de Janeiro. In: FARRET, R. L. (org.) Modernização, exclusão e a espacialidade do futuro. Anais do VI Encontro Nacional da ANPUR. Brasília: ANPUR, 1995, p. 394-406.

FURTADO, Celso. Teoria e política do desenvolvimento econômico. São Paulo: Paz e Terra, 2000.

GRZYBOWSKI, Cândido. O Globo, 7 de dezembro de 2006, p. 7. HARVEY, David. A produção capitalista do espaço. São Paulo: Ed. Annablume, 2006.

. Condição pós-moderna. São Paulo: Edições Loyola, 1994.

IERMB. Aglomeracions Metropolitanes Europes. Revista PAPERS, n. 50. Barcelona: IERMB (Institut D’Estudis Regionals i Metropolitans de Barcelona), 2009.

LEFEBVRE, Henri. El derecho a la ciudad: historia, ciencia, sociedad. Barcelona: Ediciones Península, 1978.

. Espacio y política, el derecho a la ciudad II. Barcelona: Ediciones Península, 1976.

LENCIONI, Sandra. Condições gerais de produção: um conceito a ser recuperado para a compreensão das desigualdades de desenvolvimento regional. Revista Scripta Nova, Revista electrónica de geografía y ciencias sociales, vol. XI, n. 245, 1 de agosto. Barcelona: Universidade de Barcelona, 2007.

. Da metrópole como estratégia desenvolvimentista à metrópole como sobrevida do capitalismo. In: PEREIRA, Paulo César Xavier e HIDALGO, Rodrigo. Producción inmobiliaria y reestructuración metropolitana en América Latina. Santiago: PUC-Chile, 2008, pp. 41-54.

- Impasses da gestão metropolitana nas regiões de Buenos Aires, São Paulo e Santiago. Revista Scripta Nova, Revista electrónica de Geografía y Ciencias 
Sociales, v. XII, n. 270, 1 de agosto. Barcelona: Universidade de Barcelona, 2008.

OLIVEIRA, Floriano. Reestruturação produtiva, território e poder no Estado do Rio de Janeiro. Rio de Janeiro: Ed. Garamond, 2008. 304 p.

SANTOS, Milton. A natureza do espaço: técnica e tempo, razão e emoção. São Paulo: Editora Hucitec, 1996.

. O retorno do território. In: SANTOS, Milton; SOUSA, Maria A. e

SILVEIRA, Maria L. Território: globalização e fragmentação. São Paulo: Editora Hucitec/ANPUR, pp.15-21, 1996.

SASSEN, Saskia. El reposicionamiento de las ciudades y regiones urbanas en una economía global: ampliando las opciones de política y gobernanza. Revista EURE, v. 33, n. 100, Chile, Santiago, pp. 9-34, 2007.

SCOTT, Allen J. Regions and the world economy: the coming shape of global production, competition, and political order. New York: Oxford University Press Inc., 1998.

Global City-Regions and the New World System. Los Angeles Websites Reserch the Economic Geography et University of California, 1999. Disponível em (www.geog.ucla.edu/ econgeog/research/research.htm-9k). Acesso em 29 de maio de 2003.

SOJA, Edward W. Geografias pós-modernas: reafirmação do espaço na teoria social crítica. Rio de Janeiro: Jorge Zahar Editor, 1993.

. O desenvolvimento metropolitano pós-moderno nos EUA: virando Los Angeles pelo avesso. In: SANTOS, Milton et alli (orgs.) Território: globalização e fragmentação. São Paulo: Editora Hucitec/ANPUR, 1996.

VAINER, Carlos B. As escalas do poder e o poder das escalas: o que pode o poder local. Ética, Planejamento e Construção Democrática do Espaço. Anais do IX Encontro Nacional da ANPUR, v. I. Rio de Janeiro: ANPUR, 2001, pp.140152.

Recebido em 30 de setembro.

Aceito para publicação, em 20 de outubro de 2009. 